\title{
Echocardiographic detection of congenital heart disease in the fetus: present and future
}

\author{
Lindsey D Allan
}

\section{Table}

- Family history of congenital heart disease-previous child or paren affected

- Maternal diabetes

- Fetal arrhythmia

- Fetal hydrops

- Extracardiac fetal anomaly

- Exposure to cardioteratogenic drugs-for example, lithium, anticonvulsants

Babies Hospital, Columbia Presbyterian Medical Center, New York, New York, USA L D Allan

Correspondence to: Professor L D Allan Professor of Pediatrics (in Obstetrics, and Gynecology), Babies Hospital, Columbia Presbyterian Medical Center, 3959 Broadway 2-North, New York, NY 10032, USA.

Accepted for publication 16 February 1995
During the 1970s, ultrasound rapidly developed into a reliable tool for the prenatal diagnosis of malformations in many organ systems. ${ }^{12}$ However, the cardiovascular system was avoided, partly because real-time imaging was not yet available and partly because of the apparent anatomical complexity of the heart and the variety of structural abnormalities. It was not until the advent of cross sectional imaging in the late 1970 s and early 1980s, that cardiac imaging became practical. At this time paediatric cardiologists were beginning to learn the value of the echocardiogram for the diagnosis of congenital heart disease in postnatal life. ${ }^{3}$ Simultaneously, they became aware of the improved quality of prenatal imaging and several workers in different centres made a systematic study of the fetal heart. ${ }^{4-6}$ Over the next few years, it became established that normal fetal cardiac anatomy could be reliably identified and that the diagnosis of structural abnormality was also possible. ${ }^{47}$ Since then, improved resolution of ultrasound equipment and the addition of pulsed, continuous wave and colour flow Doppler have all added to the information that can be obtained prenatally.

\section{Case selection and screening}

In the early 1980 s fetal echocardiographers focused their efforts on mothers at an increased risk of having offspring with congenital heart disease. The table lists the high risk groups that are selected for study. When a previous baby has been affected by congenital heart disease the risk of recurrence in a subsequent pregnancy is 1 in $50 .{ }^{8}$ This risk varies according to the type of congenital heart disease in the index case. ${ }^{9}$ The risk in those pregnancies where a parent is affected is also increased and may be as high as $10 \% .^{10}$ Maternal diabetes is reported to double the risk of congenital heart disease in the fetus, although this risk may be lower in a well controlled diabetic population. ${ }^{11}$ Non-immune fetal hydrops can be caused by intrauterine cardiac failure secondary to structural heart disease. ${ }^{12}$ In addition, where an extracardiac abnormality is detected in the fetus, the fetal heart should be studied as there is an increased incidence of congenital heart disease in association with other anomalies. A cluster of anomalies may indicate the pres- ence of a genetic syndrome, caused by either a gene defect or a chromosomal anomaly. Some drugs such as lithium and the anticonvulsants have been reported to increase the incidence of congenital heart disease if taken in early pregnancy.

Although it is important to select high risk groups and to offer these parents a detailed fetal echocardiogram, only $10 \%$ of children born with congenital heart disease have a high risk factor identifiable in the pregnancy. If fetal echocardiography is confined to the high risk groups, it will have little impact on paediatric cardiological practice. However, in 1986, an idea, put forward by a French group $^{13}$ had the potential to extend enormously the impact of fetal echocardiography. This was to use the expertise of the obstetrician performing routine obstetric scans to detect congenital heart malformations. The French group suggested simplifying the evaluation of the heart to the examination of one cardiac section-the four chamber view-and teaching the ultrasonographer to obtain and interpret this view. This resulted in the detection of cardiac anomalies in about 2 per 1000 pregnancies scanned. This teaching technique has also been employed with a high degree of success in the United Kingdom $^{14}$ despite the fact that, unlike France, there is no organised routine scanning policy.

\section{Normal fetal heart scanning}

A four chamber view of the fetal heart can be obtained with standard ultrasound equipment in every pregnancy from 18 weeks' gestation and with the use of modern, high resolution vaginal transducers in many cases as early as 12 weeks' gestation. Ultrasonographers are taught to analyse this section in an organised fashion to check the heart's position and size as well as the structure of the atrioventricular connection which is seen in this section. Other parts of the fetal heart can be imaged in various projections, both longitudinal and transverse. ${ }^{15}$ All the cardiac views familiar in postnatal life can be obtained, with some further views that are unique to the fetus. Although they are more difficult for the ultrasonographer to understand and more timeconsuming to obtain, the venous and great artery connections can be displayed in every fetus after 18 weeks' gestation. An increasing 
number of obstetric units routinely offer a fetal anatomy scan at 18 weeks' gestation and in addition, scanning is becoming more detailed and expert. As a result, all forms of fetal anatomical malformation are more frequently detected than before. ${ }^{16}$ This routine scan should include at least a four chamber view of the heart. At this stage in pregnancy, many major abnormalities can be detected or excluded. Currently, over $80 \%$ of the positive referrals to our centre are those in which the obstetrician has not found a normal four chamber view.

Abu-Harb et al (pages 192-8) arbitrarily divided 1347 cases of congenital heart disease, seen over a 7 year period in a single geographical area, into those they considered "detectable" and "undetectable" antenatally. ${ }^{17}$ They judged $15 \%$ of cases to be "detectable". Taking a figure of $20 \%$ success in identifying "detectable" lesions, they conclude that prenatal diagnosis will have a negligible effect on the practice of paediatric cardiology. But many ultrasound scanning units can achieve a rate of detection closer to $100 \%{ }^{14}$ and as experience and expertise grow, many can also detect a good proportion of the lesions the authors considered "undetectable". I see no reason why all the major forms of congenital heart disease, which constitute about three of eight examples of congenital heart disease per 1000 live births, should not become detectable during routine scanning, especially with continuing advances in the quality of ultrasound images. If $50 \%$ of parents chose to interrupt the pregnancy, absolute numbers of cases of congenital heart disease would drop by about $20 \%$. More importantly, however, cases identified in utero are in general the complex forms of cardiac malformation that are highly resource intensive. These cases occupy a disproportionate amount of the paediatric cardiologist's time and effort because of the requirements for repeated investigation, multiple operations and long-term follow up. If half of these pregnancies are terminated, I do not think that this will leave paediatric cardiologists idle but they may have to recognise that the growth areas in their specialty will be in fetal diagnosis and in the care of the adult with congenital heart disease. However, this kind of speculation is not very useful.

There is clear evidence that it is possible to teach ultrasonographers to evaluate the fetal heart. The standard of fetal anatomical evaluation is continually improving and obstetric scans require the same level of skill and experience as echocardiographic examination of adults.

\section{Cardiac malformations}

Since 1980, over 12000 high-risk pregnancies have been referred for study in the Fetal Cardiology Unit at Guy's Hospital. Over 1000 fetal cardiac abnormalities have been detected. ${ }^{18}$ Because the four chamber view is emphasised, the lesions preferentially detected prenatally are those where the four chamber view is abnormal. Conversely, lesions, such as complete transposition, that are common postnatally but in which the four chamber view is normal are under-represented in the prenatal series. Thus the range of disease seen in fetal life is different from that seen in infants. It is also influenced by the selection of fetuses with extracardiac malformations for fetal echocardiography. For example, nearly all the ventricular septal defects we have detected in utero have been large and associated with extracardiac malformations, especially when the fetus has a chromosomal anomaly. This accounts for very few of the ventricular septal defects seen in children.

Because it produces an abnormal four chamber view and is associated with extracardiac lesions the most common lesion seen prenatally is an atrioventricular septal defect. ${ }^{19}$ As an isolated cardiac defect, it will commonly be associated with trisomy 21 , or it may occur in the setting of atrial isomerism. The next most frequent lesion seen is the hypoplastic left heart syndrome, which until recent palliative surgery was introduced, was a universally fatal lesion in the first days of life. In the United Kingdom more than half the cases of hypoplastic left heart syndrome are probably detected in the fetus and most parents choose to interrupt the pregnancy. This has led to a detectable fall in the number of cases presenting in infancy. ${ }^{20}$ Almost all forms of congenital heart disease have been recognised in the fetus, and the diagnosis of most follows the same rules as for the echocardiographic diagnosis in postnatal life.

\section{Accuracy and confidence intervals}

The accuracy achieved in the prenatal diagnosis of cardiac malformations can be high. Over $70 \%$ of our cases had anatomical follow up and there was close correlation between the echocardiographic and pathological results, even in complex lesions at early gestations. The degree of correlation also improved with experience. In our series, false negative diagnoses were made in less than $0.5 \%$ of cases. Lesions that were overlooked were mainly minor defects, such as small ventricular or atrial septal defects. False positive diagnoses have been even less common and have mainly involved the difficulty of excluding the diagnosis of coarctation of the aorta in the later stages in pregnancy. Coarctation is suspected where the right ventricle and pulmonary artery are dilated relative to the left ventricle and aorta. Examination of the long axis of the aortic arch directly is not always diagnostic or even useful. ${ }^{21} \mathrm{~A}$ presumptive diagnosis, therefore, sometimes has to be made until it is definitively excluded postnatally. Right ventricular dominance can also be a sign of abnormal pulmonary venous drainage, as indicated by Papa et al. ${ }^{22} \mathrm{His}$ paper demonstrates the difficulty in interpreting this sign correctly and in identifying normal pulmonary venous drainage in images that are less than perfect. I would add to this 
that normal pulmonary venous drainage cannot be reliably diagnosed unless the flow can be detected entering the correct site in the left atrium on colour flow mapping and that abnormal pulmonary venous drainage should not be diagnosed unless the collecting channel and site of drainage can be clearly identified.

\section{Counselling and outcome}

The most important skill of prenatal diagnosis is counselling the parents when an abnormality is found. Every parent brings different views, experience, and social circumstances to decisions about continuing a pregnancy in which there is fetal malformation. Parents must feel able to choose. If a major cardiac anomaly is diagnosed before 20 weeks more than half the parents will choose to interrupt the pregnancy after counselling. Where a healthy adult life is unlikely, many parents see continuation of the pregnancy as unacceptable. Because the most severe lesions are selected to come to our attention, there is a high mortality in continuing pregnancies. In our series, only about a third of detected cases survived in the short term, with the greatest loss occurring in intrauterine or early neonatal life. Some view the elective prevention of major cardiac malformations as a very negative aspect of fetal cardiology. But for the hundreds of parents this difficult and unwelcome decision has avoided much suffering for both the child and the family. Prenatal diagnosis of congenital malformations is still useful when termination of pregnancy is not an option or where diagnosis is made late in gestation. Parents can be prepared for the management of the delivery, the early treatment plan for their infant, and the likely outcome. Delivery in a cardiac centre gives the infant the best chance of survival after surgery because the clinical state can be optimised from birth and transfer of a sick neonate is avoided. ${ }^{23}$

Much has been learnt by observation of the fetus with heart disease in utero. We have seen unusual types of malformation that are not commonly seen postnatally, for example, the dysplastic tricuspid valve with severe cardiomegaly. ${ }^{24}$ Greater ascertainment of disease has allowed us to be more accurate in determining the recurrence of disease within families. This has shown us unusual patterns of recurrence, for example, the high rate in left heart disease. Unexpected associations between cardiac and extracardiac malformations have been defined-for example, the strong association of fetal tetralogy of Fallot with multiple malformations. ${ }^{25}$ The most interesting finding has been the observed evolution of cardiac lesions during fetal growth, for example, the progression of aortic stenosis to atresia and the associated failure of left heart growth, leading to left heart hypoplasia. ${ }^{26}$ This tendency to progression has been observed in other obstructive lesions, such as pulmonary stenosis and coarctation of the aorta. The observation of progression in critical aortic stenosis coupled with a high mortality in this condition when treatment took place postnatally, led to the idea of prenatal treatment. At the same time, balloon valvuloplasty was increasingly successful in treating aortic stenosis postnatally and intracardiac puncture for obstetric techniques became established as a safe procedure. This resulted in attempts at prenatal balloon valvuloplasty in four fetuses. ${ }^{27}$ This technique has been associated with long term survival and is promising for the management of a few selected conditions in the fetus.

\section{The place of fetal echocardiography}

There is now an established place for fetal echocardiography within the practice of paediatric cardiology. Fetal echocardiography can predict structural cardiac anomaly with accuracy. Initial routine screening, with referral of suspected abnormal pregnancies to a specialist centre, has become well established in the United Kingdom. With further extension of teaching programmes, detection of cardiac malformations during obstetric scanning is certain to increase. Concentration of the experience of evaluating anomalies in referral centres will increase the accuracy of diagnosis and optimise management of patients. The purpose of fetal echocardiography is not to terminate all affected pregnancies, but to provide information and ideal care for the patient. The technique has expanded our knowledge and understanding of congenital heart malformations and will continue to do so as imaging improves. Prenatal treatment of structural heart disease can be successful in the few cases where it is appropriate.

1 Garrett WJ, Grimwald G, Robinson DE. Prenatal diagnosis of fetal polycystic kidney by ultrasound. Aus-NZ $\mathcal{f}$ Obstet Gynaecol 1970;10:7-9.

2 Campbell S, Holt EM, Johnstone FD, May P. Anencephaly: early ultrasonic diagnosis and active manAnencephaly: early ultrasonic diagn

3 Tajik AJ, Seward JB, Hagler DJ, Mair DD, Lie JT. Twodimensional real-time ultrasonic imaging of the heart and great vessels. Technique, image orientation, structure identification and validation. Mayo Clin Proc 1978 53:271-303.

4 Kleinman CS, Hobbins JC, Jaffe CC, Lynch DC, Talner NS. Echocardiographic studies of the human fetus: Prenatal diagnosis of congenital heart disease and cardiac dysrhythmias. Pediatrics 1980;65:1059-67.

5 Sahn DJ, Lange LW, Allen HD, Goldberg SJ, Anderson $\mathrm{C}$, Giles $\mathrm{H}$, et al. Quantitative real-time cross-sectional echocardiography in the developing normal human fetus and newborn. Circulation 1980;62:588-97.

6 Allan LD, Tynan MJ, Campbell S, Wilkinson JL, Anderson RH. Echocardiographic and anatomical correlates in the fetus. Br Heart $\mathcal{1} 1980 ; 44: 444-51$.

7 Allan LD, Crawford DC, Anderson RH, Tynan MJ. Echocardiographic and anatomical correlates in fetal congenital heart disease. Br Heart $\mathcal{f}$ 1984;52:542-8.

8 Nora JJ. Multifactorial inheritance hypothesis for the etiology of congenital heart diseases. Circulation 1968; 38:604.

9 Allan LD, Crawford DC, Chita SK, Anderson RH, Tynan MJ. The familial recurrence of congenital heart disease in a prospective series of mothers referred for disease in a prospective series of mothers referred

10 Whittemore R, Wells JA, Castellsague X. A second generation study of 427 probands with congenital heart defects and their 837 children. $f \mathrm{Am}$ Coll Cardiol 1994;23:1459-67.

11 Shield LE, Gan EA, Murphy HF, Sahn DJ, Moore TR. The prognostic value of hemoglobin Alc in predicting fetal heart disease in diabetic pregnancies. Obstet Gynecol 1993;81:954-7.

12 Kleinman CS, Donnerstein RL, De Vore GR, Joffe CC, Lynch DC, Berkowitz RL, et al. Fetal echocardiography 
for evaluation of in utero congestive heart failure. $N$ Engl f Med 1982;306:568-75.

13 Fermont L, De Geeter B, Aubry J, Kachaner J, Sidi D. A close collaboration between obstetricians and pediatric cardiologists allows antenatal detection of severe cardiac malformations by 2D echocardiography. In: Doyle EF, Engle ME, Gersony WM, et al, eds. Pediatric cardiology: proceedings of the second world congress. New York: Springer-Verlag, 1986;34-7.

14 Sharland GK, Allan LD. Screening for congenital heart disease prenatally. Results of a $2 \frac{1}{2}$ year study in the South East Thames Region. Br f Obstet Gymaecol 1992 99:220-5.

15 Allan LD. Manual of fetal echocardiography. Lancaster: MTP Press, 1986.

16 Saari-Kemppainen A, Karjolainen O, Ylostalo $P$, Heinon OP. Ultrasound screening and perinatal mortality: controlled trial of systematic one-stage screening in pregnancy. The Helsinki Ultrasound Trial. Lancet 1990;336: 387-91.

17 Abu-Harb M, Wyllie J, Hey E, Richmond S, Wren C. Antenatal diagnosis of congenital heart disease and Down's syndrome: the potential effect on the practice of paediatric cardiology. Br Heart f 1995;74:192-8.

18 Allan LD, Sharland GK, Milburn A, Lockhart SM, Groves AMM, Anderson RH, et al. Prospective diagnosis of 1,006 consecutive cases of congenital heart disease in the fetus. $\mathcal{F} \mathrm{Am}$ Coll Cardiol 1994;23: 1452-8.
19 Machado MVL, Crawford DC, Anderson RH, Allan LD. Atrioventricular septal defect in prenatal life. Br Heart $\mathcal{f}$ 1988;59:352-5.

20 Allan LD, Cook AC, Sullivan I, Sharland GK. Changing birth prevalence of the hypoplastic left heart syndrome birth prevalence of the hypoplastic left heart syndrome as a result

21 Sharland GK, Chan K, Allan LD. Coarctation of the aorta: difficulties in prenatal diagnosis. Br Heart $\mathcal{F} 1994$ 71:70-5.

22 Papa M, Camesasca C, Santoro F, Zoia E, Fragasso G, Giannico S, et al. Fetal echocardiography in detecting anomalous pulmonary venous connection: four false positive cases. Br Heart f 1995;73:355-8.

23 Chang AC, Huhta JC, Yoon GY, Wood DC, Tulzer G Cohen A, et al. Diagnosis, transport and outcome in fetuses with left ventricular outflow obstruction. $\mathcal{F}$ Thorac Cardiovasc Surg 1991;102:841-8.

24 Sharland GK, Chita SK, Allan LD. Tricuspid valve dysplasia or displacement in intrauterine life. $\mathcal{F} \mathrm{Am}$ Coll Cardiol 1991;17:944-9.

25 Allan LD, Sharland GK. The prognosis in fetal tetralogy of Fallot. Pediatr Cardiol 1992;13:1-4.

26 Allan LD, Sharland GS, Tynan M. Natural history of hypoplastic left heart syndrome. Int $\mathcal{F}$ Cardiol 1989;25: 341-3.

27 Maxwell D, Allan L, Tynan MJ. Balloon dilatation of the aortic valve in the fetus: a report of two cases. $\mathrm{Br}$ Heart $\mathcal{f}$ $1991 ; 65: 256-8$. 